\title{
The Concept of Special Escrow Accounts to Improve Mortgage Housing Loans in Russia
}

\author{
Submitted 18/08/19, 1st revision 20/09/19, 2nd revision 16/10/19, accepted 28/11/19
}

\section{Ekimova K.V., ${ }^{1}$ Nazarchuk N.P., ${ }^{2}$ Denisova I.P., ${ }^{3}$ Gruzdneva E.N. ${ }^{4}$}

\begin{abstract}
:
Purpose: The article aims to identify and evaluate the key determinants of improving mortgage lending in Russia. Increasing the participation of financial institutions in the application of escrow accounts is of paramount importance in terms of fine-tuning the process of improving mortgage lending in Russia.

Design/Methodology/Approach: In order to further improve housing mortgage lending, it seems necessary: firstly, to identify new opportunities that contribute to the development of a system of interaction between credit and financial organizations and borrowers in terms of using the innovative functions of escrow accounts; secondly, to highlight the functions, during the application of which the increase in the efficiency of the escrow account mechanism will be optimal; thirdly, to formulate recommendations on the implementation of the necessary changes in the process of applying escrow accounts, taking into account the peculiarities of mortgage lending in Russia.

Findings: To fully take into account the potential impact of special escrow accounts on the process of interaction between the lender and the borrower, an additional escrow account functionality was developed, aimed at improving mortgage lending.

Practical Implications: The results of the study can be put into practice in order to expand the range of escrow account functions used in the process of mortgage lending in Russia.

Originality/Value: The main contribution of this study is the emphasis on the need to introduce innovative approaches to increase the functionality of escrow accounts used in the process of mortgage lending in Russia.
\end{abstract}

Keywords: Housing mortgage lending, escrow account, collateral, escrow agent.

JEL code: G21, K19, R21, E59.

Paper Type: Research article: Mortgage Lending.

\footnotetext{
${ }^{1}$ Professor, State University of Management, Moscow, Russian Federation, inf@guu.ru

${ }^{2}$ Senior Lecturer, Department of Economics, Tambov State Technical University (TSTU), nazarchuk.natali@mail.ru

${ }^{3}$ Associate Professor of the Department of Finance, Rostov State Economic University of Economics, Rostov-on-Don, Russian Federation, denis8663@mail.ru

${ }^{4}$ Head of the Department of Graduate and Doctoral Studies, Rostov State Economic

University of Economics, Rostov-on-Don, Russian Federation, gruzdneva_k@mail.ru
} 


\section{Introduction}

The relevance of the research topic is determined by the need to search for new tools and technologies that ensure the creation of additional opportunities when using an escrow account to further improve mortgage lending in Russia. In the context of housing mortgage lending, an escrow account is a special account opened by an escrow agent (usually a bank) to account for and block money received by an escrow agent from the account holder - a participant in shared construction in payment of the price of the contract for participation in shared construction in relation to the relevant property - in order to transfer such funds to the developer subject to the proper fulfillment of contractual obligations. The use of an escrow account allows the parties of the transaction to ensure proper fulfillment of obligations and minimize the risk component. The search and subsequent implementation of innovative approaches aimed at increasing the functionality of escrow accounts currently used in the process of acquisition of housing by borrowers will optimize the process of improving mortgage housing lending in Russia.

In the current conditions of the development of mortgage housing lending in Russia, the key role is played by the creation of effective financial instruments that ensure guaranteed fulfillment of the obligations stipulated for each of the parties to the contract, within the framework of legal relations arising at all stages of transactions related to the purchase of housing by citizens. The effectiveness of the mortgage system largely depends on the state of the market and the factors affecting it. The degree of influence of factors is not constant at different periods of time, which causes a change in trends in the mortgage lending market. Trends can be interpreted as stable relationships that determine the direction of economic processes (Malysheva, 2018; Bernadus et al., 2018).

The main regulatory legal acts of the Russian Federation governing the mortgage sector and transactions related to the shared construction of multi-dwelling houses have been supplemented by fundamentally new requirements that have been normatively consolidated over the past four years. An important feature of such innovations is the achievement of a new, better level of legal regulation of relations, caused by, inter alia, agreements concluded by citizens for the purchase of housing in new buildings using mortgage lending; since the development of the mechanism of housing mortgage lending is one of the most important areas for creating opportunities for individuals to purchase residential real estate, including in the process of a phased transition, from raising financial means for shared construction of apartment buildings and other real estate to other forms of housing finance that protects the rights of citizens and reducing risks for them.

One of the main legislative innovations that provide a high level of financial security to individuals who are members of shared construction is the use of escrow accounts. Guaranteed security of home buyers, along with total control over the 
fulfillment of obligations by an independent bank that performs the functionality of an escrow agent, are a combination of conditions that contribute to increased demand for such a model of transactions.

Potential homebuyers who took a wait-and-see attitude in 2018 and many times prior due to high risks associated with unfinished and lost money, are gradually becoming aware of the expediency and effectiveness of using escrow accounts, as this method of acquiring housing eliminates the indicated risks that, up to and including 2017, were the main reason for rejecting mortgage lending and housing transactions in general; since when risk events occurred, the client could continue to pay the mortgage for the dilapidated, unfinished object for many years.

Mortgage loan is an important condition for the economic and social development of the country. It is the positive experience of developed and some developing countries that shows the universality of a mortgage loan, which by increasing the availability of housing for the population helps to reduce social tension and increase the well-being of citizens. In addition, it stimulates the adequate functioning of construction and related industries in the real sector of the economy, activates the banking system and the stock market, slows inflation, increases investment activity as well as social and economic stability of the society (Meleshenkova, 2016).

Measuring the state and identifying trends in the mortgage lending market are a prerequisite for the effective actions of the regulator, lenders and borrowers, participants in the financial market (Nazarchuk, 2017).

Currently, the funds necessary for buyers to pay for apartments in new buildings are not transferred to the settlement accounts of developers; starting July 1, 2019, these financial resources are accumulated in special escrow accounts. In this regard, the construction of apartment buildings is carried out with the primary attraction of bank funds; that is, project financing is being implemented to a certain extent which may indicate the completion of work in the form of an equity agreement.

\section{The Role of Escrow Accounts in Mortgage Lending}

Federal Law dated 01.07.2018 No. 175-FZ "On Amending the Federal Law" On Participation in the Shared Construction of Multi-Apartment Buildings and Other Real Estate Objects and on Amending Certain Legislative Acts of the Russian Federation "and Certain Legislative Acts of the Russian Federation" introduced a number of changes including the peculiarities of the builder attracting funds from participants in shared construction. In the case of placing such funds on escrow accounts, namely, it was legislatively stipulated that in order to attract the builder money from participants in shared construction for the construction of apartment buildings and other real estate by placing such funds in escrow accounts, all participants in shared construction in relation to an apartment building and other property shall make cash on account of the payment of the cost of participation 
contracts in shared construction on escrow accounts opened with an authorized bank. At the same time, escrow is the most universal mechanism capable of enforcing a wide range of contracts conveniently and effectively, which means that it could become a popular means of securing obligations in Russia (Novikova, 2013).

In the context of housing mortgage lending, an escrow account is a special account opened by an authorized bank (escrow agent) to record and block money received by the bank from the account holder - a participant in shared construction (depositor) to pay the price of an agreement on participation in shared construction in relation to multi-unit home and/or other real estate object, in order to transfer such funds by the escrow agent to the developer (beneficiary). If the authorized bank interacts with customers using remote banking systems - an application for opening an escrow account - an escrow account agreement can be filled out and signed with a simple electronic signature using the remote banking systems of the authorized bank in accordance with banking rules. Funds are credited to the escrow account after the registration of an agreement on participation in shared construction for a term of conditional escrow of funds, which cannot exceed the term of commissioning of an apartment building and/or another property indicated in the project declaration for more than six months. Interest on the amount of funds held in an escrow account is not charged. Remuneration to an authorized bank - that is an escrow agent - in an escrow account is not paid.

Along with this, article 860.7 of the Civil Code of the Russian Federation provides for a somewhat expanded interpretation of identical rules, including that the rights to funds held in an escrow account belong to the depositor until the grounds for the transfer of funds to the beneficiary arise and after the specified date to the beneficiary. At the same time, obligations under the escrow account agreement may be contained in addition to the escrow account agreement in another agreement under which the bank is the escrow agent. The remuneration of the bank as an escrow agent cannot be charged from the funds held in the escrow account, unless otherwise provided by the contract. The standard algorithm of actions using an escrow account in a simplified order is as follows (Figure 1).

Figure 1. The algorithm of actions using an escrow account

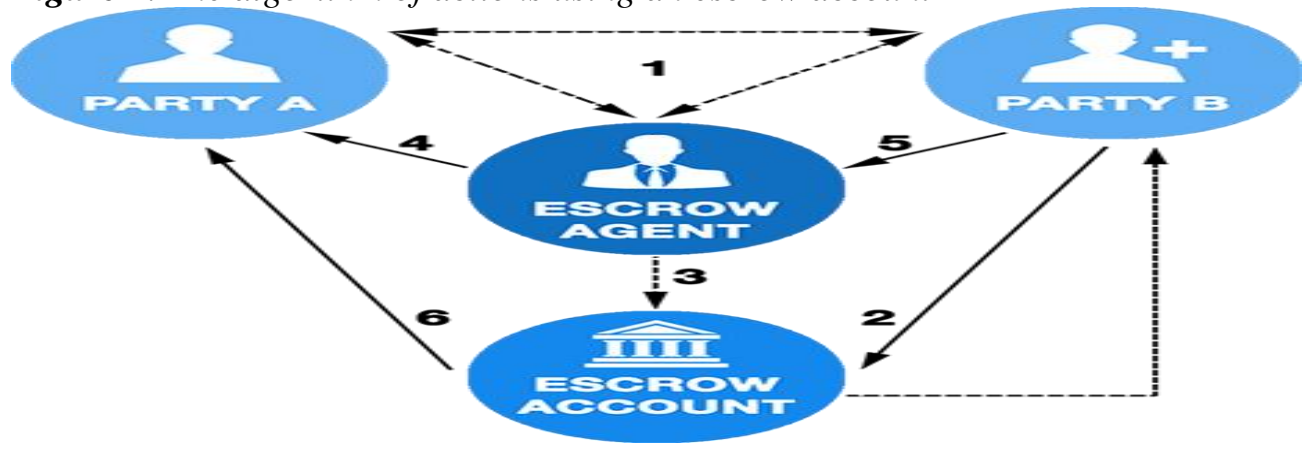


In modern conditions, the degree of development of the mortgage market is one of the key factors determining the level of housing provision of the population in Russia. In this regard, there is considerable potential for expanding the functions of escrow accounts, which is further evidenced by the following data. According to the analysis of the dynamics of putting housing into operation for 2018 and JanuarySeptember 2019 in Russia, the beginning of 2018 should be distinguished, characterized by an increase in the commissioning of individual houses, which, in turn, is due to the need to accelerate the process of registering residential real estate in the context of the expected cancellation of country amnesty.

Moreover, since August 2019, the formula in accordance with which the calculation of information on housing construction is carried out takes into account residential buildings erected by owners on land plots intended for gardening. Such residential properties located on land provided for horticulture were not previously taken into account due to the phased entry into force of certain norms of the Federal Law of July 29, 2017 No. 217-FZ, “...on the conduct by citizens of gardening and horticulture for their own needs and on amendments into separate legislative acts of the Russian Federation."

An important role for the growth of the total commissioning of housing in 2018 belongs to the emergence of new requirements for developers of apartment buildings, the construction of which used the previously existing methods of appropriate equity participation. Since the entry into force of certain regulatory legal acts, significant changes were expected in the algorithm for legislative regulation of construction with shared participation; and most developers, with the aim of completing facilities under the old rules, prudently increased the number of square meters of housing under construction, which led to a significant increase in the volume of commissioning of housing in Russia for the period January-September 2018 compared with January-September 2019.

In the territory of the Russian Federation for the period January-September 2019, 638.9 thousand apartments were commissioned in multi-apartment and residential buildings built by the population, with a total area of 48.9 million square meters, which amounted to $106.9 \%$ of the corresponding period last year (Rosstat, 2019).

Table 1. Construction of residential buildings in the constituent entities of the Russian Federation in January-September 2019 (Rosstat, 2019)

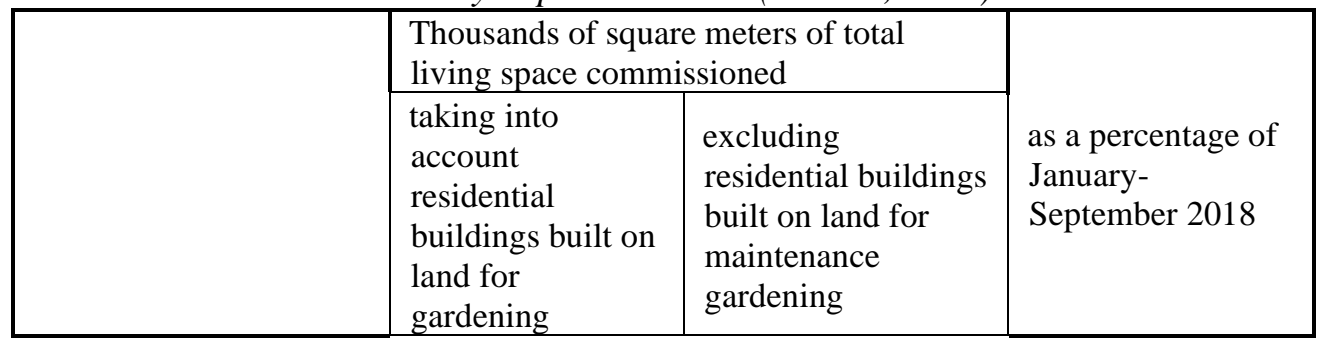




\begin{tabular}{|l|l|l|l|}
\cline { 2 - 3 } Russian Federation & 48916,0 & 48585,2 & 106,9 \\
\hline Leningrad region & 1678,8 & 1678,7 & 80,4 \\
\hline city Saint Petersburg & 1068,6 & 1068,6 & 75,1 \\
\hline Krasnodar region & 2882,8 & 2880,7 & 107,5 \\
\hline Rostov region & 1816,4 & 1814,0 & 117,6 \\
\hline Stavropol region & 739,6 & 734,5 & 115,2 \\
\hline Republic of Tatarstan & 1771,4 & 1771,4 & 102,6 \\
\hline Saratov region & 667,2 & 666,9 & 90,6 \\
\hline Ulyanovsk region & 621,8 & 621,8 & 111,5 \\
\hline Sverdlovsk region & 1194,3 & 1190,1 & 106,4 \\
\hline Novosibirsk region & 1020,1 & 1010,6 & 107,8 \\
\hline
\end{tabular}

In the process of prospective planning of the average level of the interest rate on a mortgage loan, the total volumes of commissioning housing in Russia as a whole within a three-year period are to be taken into account with the subsequent approval of the corresponding plan at the level of the relevant federal ministry. It is necessary to make the mortgage more accessible, oriented to different segments of the population. When developing socially-oriented mortgage programs, their diversity, loan terms, and gradual decrease in interest rates on payments should be taken into account, first of all (Tarasova and Baronin, 2017).

The activity plan of the Ministry of Finance of the Russian Federation for 2019-2024 provides for the gradual expansion of opportunities for the acquisition (construction) of housing facilities using modern mortgage lending tools. At the same time, it is expected that the average interest rate on a mortgage loan by 2024 should be $7.9 \%$. Along with the planned increase in liquidity and a decrease in credit risk for banking organizations, the achievement of the specified target indicator of less than $8 \%$ by 2024 will be facilitated by ensuring access to effective refinancing of existing loans issued for the purchase of residential real estate in the primary market. The key factors for the mortgage remain inflation indicators and the key rate of the Central Bank. In addition, real loan volumes will be determined by liquidity reserves in the banking sector (Korsunova, 2018).

Regarding the planned number of mortgage loans issued, an annual positive dynamic is expected and by 2024 the value of this indicator is projected at 2.26 million units, which is also provided for in the Passport of the national project "Housing and Urban Environment", which is approved by the Presidium of the Council under the President of the Russian Federation Federation for Strategic Development and National Projects (Minutes No. 16 of December 24, 2018).

One of the main goals of the national project "Housing and Urban Environment" is to provide affordable housing for middle-income families, including creating opportunities for them to purchase (build) housing using a mortgage, the rate at which should be less than 8 percent (Passport of the federal project "Mortgage", approved by the minutes of the meeting of the project committee for the national 
project "Housing and urban environment" dated December 21, 2018 No. 3, 2018). The structure of the specified national project, including federal projects "Mortgage" and "Housing" with an implementation period from 10/01/2018 to $12 / 31 / 2024$. So, in order to achieve the main goal of the federal project "Mortgage", by 01.07 .2020 it is planned to increase the attractiveness of mortgage securities for investors with a guarantee of JSC "House of the Russian Federation". In general, only a combination of the following factors can make a mortgage truly affordable: the degree of development of the real estate market; property value; volume of commissioning of new real estate; income level of the population, development of the capital market and banking system; regulatory and other factors of both an external and internal economic nature (Zhirakovskaya, 2017).

The average price of one square meter of the total area of apartments (all types of apartments) in the primary housing market in Russia as a whole for the period January-September 2019 amounted to 61.7 thousand rubles, which is 1.8 thousand rubles, or $3 \%$ higher, than the value of such an indicator for January-September 2018 (Rosstat, 2019).

According to the information of the analytical center DOM.RF, at the beginning of October 2019, the total volume of projects using escrow accounts exceeded 19 million square meters in Russia as a whole, which is $19.6 \%$ of the total number of new buildings. One month later at the beginning of November 2019, the total volume of projects involving escrow accounts amounted to 23.1 million square meters; and according to the new rules, 2289 apartment buildings from 963 developers are already under construction, with more than 23 open, 1 thousand escrow accounts attracted funds of individuals in an amount exceeding 74.2 billion rubles (Financial Institute for Housing Development "DOM.RF", 2019).

\section{The Functionality of Escrow Accounts}

Given the specifics of the current legal regulation of relations associated with the use of funds of individuals for the shared construction of residential real estate, a number of decisions have been made such as: the provisions of the Federal Law of June 27, 2019 No. 151-FZ "On Amendments to the Federal Law"; on Participation in the Shared Construction of Multi-Apartment Buildings and other real estate objects; amendments to some legislative acts of the Russian Federation; certain legislative acts of the Russian Federation; a number of necessary amendments to the basic Federal Law dated December 30, 2004 No. 214-FZ "On participation in shared construction of apartment buildings and other real estate objects and on amendments to some legislative acts of the Russian Federation”.

In such circumstances, the use of certain financial instruments, including special escrow accounts, has become an inherent necessity due to requirements enshrined in federal law. So, if the construction of an apartment building is carried out at the expense of the funds provided to the Borrower strictly for certain purposes on the 
basis of the concluded syndicated loan agreement, then persons participating in shared construction are required to ensure that the necessary amount is paid to pay the cost of shared construction contracts on special escrow accounts, which are open in banks belonging to the syndicate of creditors in accordance with the terms of the specified syndicated loan agreement.

According to the California Financial Code, "escrow" means any transaction in which one person transfers a document, money or title deed to movable or other property in order to sell, transfer, encumber or transfer movable or immovable property to another person, immovable property or other value to a third party for storage until the occurrence of an event or the fulfillment of a certain condition (California Financial Code, 2017).

With regard to the situation related to the purchase of housing on a mortgage using an escrow account, it should be noted that, taking into account the legal norms that came into force in August 2019, the pledge of rights of claim of a participant in shared construction under an agreement on participation in shared construction, acquired at the expense of credit or borrowed funds, the indicated rights of claim must be pledged to the person who granted the loan or loan from the moment of state registration of the pledge of rights of claim of the participant in shared construction and in the Unified State Register of Real Estate.

During state registration of the property right of a participant in shared construction to an object of shared construction, the pledge of the rights of claim of the participant in shared construction is replaced by the pledge of the object of shared construction and such an object is pledged to the pledge holder of the rights of claim of the participant in shared construction under an agreement on participation in shared construction. State registration of a mortgage in this case is carried out simultaneously with state registration of the property right of a participant in shared construction.

The new system of such settlements is structured taking into account the fact that the funds owned by buyers of residential real estate and placed on escrow accounts, after state registration of an agreement on participation in shared construction, are subject to deposit (freezing) until the first entry in the unified state register of real estate on the state registration of ownership of an apartment in a finally completed apartment building.

In the occurrence that events are inconsistent with the conditions set forth in the escrow account agreement or other agreement providing for the fulfillment of certain obligations by both the developer and the buyer of the apartment, the bank, which is an escrow agent, within its competence considers the matter of further actions until the return cash to the buyer. If bankruptcy proceedings are initiated with respect to the escrow agent, the home buyer will not lose his money and will receive it in full from the Deposit Insurance Agency, which guarantees payment of up to 10 million 
rubles, after which a new escrow account agreement will be concluded with an authorized bank. In any case, when adverse events occurring for the home buyer and negative events independent of him, his money is well protected, which indicates the absolute safety of such mortgage loans and at the same time indicates an increase in the attractiveness of acquiring apartments using the modern escrow account mechanism. Consequently, an increase in the total volume of transactions using escrow accounts will contribute to the dynamic development of housing lending in Russia.

Currently, a norm has been fixed at the level of federal legislation that allows, with an electronic digital signature from users, to carry out actions aimed at remotely opening an escrow account. Along with this, by 2024, the mortgage market in Russia will be converted into electronic format, which will allow you to receive mortgage loans in electronic form. Consequently, the risks of mortgage lenders will be reduced due to the possibility of real-time and electronic access to full access to information about borrowers, the procedure for assessing the financial viability of the applicant for a mortgage loan will be modernized, and the costs of underwriting due to the introduction of an artificial intelligence system will be optimized at all stages of the process of providing mortgages to customers.

In any case, large-scale digitalization in the banking sector is an inevitable stage in the development of banking services, including those related to housing mortgage lending. Some credit and financial organizations of the Russian Federation are already introducing electronic digital tools into widespread practice where, as a rule, biometric data are used to digitally identify citizens, since such data is necessary to provide various banking services on a remote basis, that is, at a given time potential home buyers already have the opportunity in electronic format to interact with the bank both for independently opening an escrow account and for obtaining a mortgage loan.

Returning to the chronology of further processes related to the escrow account, it should be noted that the funds deposited into the escrow account are not later than ten working days from the moment the bank receives information from the Unified State Register of Real Estate confirming the state registration of ownership of one shared construction object as part of an apartment building and/or other property, are transferred by the escrow agent to the developer or are sent to pay for obligations under a loan agreement, but in any case, summarizing the legally regulated algorithm for using the escrow account mechanism, a unique feature is seen that the moment of state registration of ownership of the shared construction object serves as a kind of decision point for the escrow agent to continue the transfer process cash from escrow account.

Given the fact that the information contained in the Unified State Register of Real Estate is open and, in some cases as part of interagency cooperation in real time, may be available to users with the necessary authority, therefore the escrow agent 
has access in real time to such information contained in the Unified State Register of Real Estate. This will allow the bank to quickly receive the necessary information immediately from the named register. That is, in simplified terms, a bank that is an escrow agent and at the same time having operational access to information contained in the Unified State Register of Real Estate will not wait (the waiting time sometimes has a very long period) until the necessary information is provided to it by the developer or other authorized person, and will be able to see them on their own immediately, as soon as the registrar from Rosreestr makes the appropriate registration record while assigning it a unique number. If this innovation is implemented in practice, this will significantly reduce the time interval for making a decision on transferring funds from an escrow account (it is assumed that funds will be transferred from an escrow account as soon as possible from the moment the escrow agent becomes aware of the relevant state registration), which will also minimize the risks of falsification of registration information on the way from Rosreestr to an escrow agent. Such an innovation will optimize the escrow account mechanism and to a certain extent will contribute to improving the process of housing mortgage lending

Summarizing the totality of the above circumstances related to the use of escrow accounts, it is important to note that the possibility of charging interest on the amount of funds held in an escrow account has not been established at the legislative level, which may indicate the underutilization of the potential for the effective use of the escrow account mechanism, since the accrual of such interest may be an additional incentive for settlements through escrow accounts. As a result of this the number of customers wishing to use an escrow account will enhance the attractiveness of such transactions. It should be noted that the process of applying an escrow account in a chain of events aimed at acquiring housing by citizens in Russia is a relatively new product (service) and against the background of the general awareness by potential customers of the fact that the escrow account mechanism allows minimizing the risk component, its use is highly promising.

In addition, an escrow account can be used to accumulate amounts on it when calculating interest and/or forfeit, as well as other payments, if provided for by the relevant contract, in cases of non-fulfillment and/or untimely (improper) fulfillment by the developer of contractual obligations, with the subsequent transfer of the indicated amounts to the escrow account of the home buyer. Or an alternative option: the escrow agent (bank) at the time of transferring to the developer the funds deposited in the escrow account of the home buyer, at the same time reduces the amount of funds to be transferred by such amount by the amount of interest and/or penalty, as well as other payments due to non-fulfillment or improper fulfillment by the developer of obligations to the home buyer. So on the escrow account there remains a certain amount belonging to the buyer of the home, which at his request is transferred to the specified account. In the context of the above measures associated with an escrow account, attention should be paid, including the availability of the possibility of indirectly reducing the cost of a mortgage. 
The above innovation will be especially in demand in cases where the costs that the home buyer is willing to incur in order to recover (at the pre-trial stage or on the basis of a court decision) from the builder the required amount will be comparable or greater than the total amount of the penalty and/or the penalty, as well as other payments due to non-fulfillment or improper fulfillment by the developer of obligations to the home buyer. At the same time, the escrow agent (bank), being a guarantor in the relevant transaction and possessing (on the basis of law or contract) the necessary powers to deduct from the builder's account a certain amount, penalty and/or forfeit, as well as other payments due to non-fulfillment or improper fulfillment by the developer of obligations to the home buyer, he can absolutely legally write off the above amount in favor of the home buyer, who placed the funds on the escrow account.

Even if an escrow agent (bank) provides for a certain fee in the form of a percentage of the amount of money forcibly collected from the developer, such innovations will not only be mutually beneficial for the parties to the contract, but also increase the level of self-discipline on the part of the builder. These circumstances additionally indicate the possibility of further improving the process of applying an escrow account, as well as mortgage lending in general.

\section{Conclusion}

Thus, the study of the additional possibility of expanding the range of functions of an escrow account in the context of improving mortgage housing lending in Russia allowed us to conclude that the use of new functions will increase the efficiency of the lender and the borrower's interaction and reduce the risk component associated with non-fulfillment or improper performance of contractual obligations, will provide stable positive dynamics of the demand for transactions using the functions of an escrow account, and optimizes the process improvement of mortgage lending.

Banking structures should form for themselves the most optimal configuration of the necessary tools in order to exhaustively use the full potential of using escrow accounts depending on the scale of work, the degree of influence on the discipline of fulfilling contractual obligations, the level of ensuring due control, financial feasibility, and applicability to one or another housing mortgage agreements.

\section{References:}

Bernadus, D., Utami, C.W., Liliana. 2018. Factor analysis of ownership behavior at family business: The case of Indonesia. International Journal of Economics and Business Administration, 6(2), 27-38.

California Financial Code. 2017. Official California Legislative Information. Available online: http://leginfo.legislature.ca.gov.

Korsunova., N.N. 2018. Prospects for the development of the HML system of Russia at the present stage. International Student Scientific Herald, 1. 
Malysheva., O.A. 2018. Trends and prospects for the development of the mortgage lending market in Russia. Journal of Science in Numbers, 41-50.

Meleshenkova., A.N. 2016. Features of the development of mortgage lending at the present stage. Synergy, 6, 98-105.

Nazarchuk., N.P. 2017. The determinants of mortgage lending. Journal of Financial Research, 1(54), 47-58.

Novikova, N.A. 2013. Prospects for escrow accounts in the Russian legislation. Journal of Scientific Dialogue: Economics. Right. Political Science, 7(19), 132-140.

Rosstat. 2019. Federal state statistic service of Russia. Available online: https://gks.ru

Tarasova, K.S., Baronin, S.A. 2017. Features of the development of mortgage lending for various social sectors of the population in the Russian Federation. Science Diary, $8(8), 10$.

Zhirakovskaya, N.A. 2017. Problems and prospects of mortgage lending in the Russian Federation. Territory of new opportunities. Bulletin of VSUES, 2, 64-73. 